\title{
A Typological Study of Tonal Systems of Japanese and Prinmi: Towards a Definition of Pitch-accent Languages*
}

\author{
Picus Sizhi Ding \\ Macao Polytechnic Institute
}

\begin{abstract}
Based on the principle of suprasegmental organization in Japanese and Prinmi (a Tibeto-Burman language of China), this paper defines a 'pitch-accent system' as one that generates tonal patterns through different placement of a marked tone on a syllable/mora in an underlying domain, which is independent of both the syllable and the word.
\end{abstract}

* An earlier version of this paper, 'Pitch-accent Systems of Japanese and Prinmi: A Typological Comparison', was presented at the Fifth Annual Conference of the Japanese Society for Language Sciences in 2003. Parts of the paper were incorporated to a talk entitled 'Typology of Tonal Systems in Languages of China' given in the Linguistics Department at University of Hong Kong in 2006. I thank the audience for their comments and discussion. In particular, I would like to thank Sam Hellmuth, Takashi Kato, K. K. Luke, Stephen Matthews, and Alexis Michaud for their interests in my typological studies of tone languages. Remaining errors and omissions in the paper rest solely with me. 
2 A Typological Study of Tonal Systems of Japanese and Prinmi:

Under this definition, the pitch-accent systems of six Japanese dialects can be analyzed uniformly. The diversity of the pitch-accent systems between these Japanese dialects and Prinmi is mainly reflected in: (1) whether or not the marked tone spreads; (2) the direction of spreading and restriction on the scope of spreading; and

(3) which edge of the underlying domain is relevant in locating the marked tone.

Keywords: pitch-accent languages, tonal systems, Japanese dialects, Prinmi, Tibeto-Burman

\section{Introduction}

Under the entry of 'pitch-accent' in The Encyclopedia of Language and Linguistics, Kubozono (1994) attempts to draw a general distinction between pitch-accent and tone (as in Mandarin) on the one hand, and between pitch-accent and stress-accent (as in English) on the other. Exactly what is meant by pitch-accent, however, is left undefined. The lack of an adequate definition of pitch-accent beyond its description as a fall in pitch has rendered comparative studies of different pitch-accent systems extremely difficult, if not infeasible.

If I may make an analogy, conducting research on linguistic typology without a clear definition of the subject is like trying to investigate the persimmon, the tomato, and the carrot in a typological study of fruits based on their similarity in color or trying to study apples of different colors by comparing red apples, green apples, and the cashew apple (which is usually yellow when ripe). The inadequacy in the first case is apparent, given our understanding on the category of fruit. Likewise, in the second case an explicit definition of apple is also essential, which cannot be assumed simply by the use of 'apple' in the name. (The cashew apple is actually the false fruit of the tree that produces the cashew nut.) To 
facilitate a comparative study of suprasegmental systems of Japanese and Prinmi, this paper endeavors to refine a rigorous definition of pitch-accent system (proposed first in Ding 2001) as a contribution to the clarification of the much used notion of pitchaccent.

Once the concept of pitch-accent system is defined precisely, in-depth typological studies of the suprasegmental system of different pitch-accent languages/dialects can be pursued. In what follows I will first sketch a typology of lexical suprasegmentals, based on a few better studied languages. A definition of pitch-accent system is then provided and discussed. Turning to a Tibeto-Burman language, I will present the essentials of Prinmi suprasegmentals and analyze its pitch-accent system with two simple parameters. This analysis will be shown to be applicable uniformly to standard Japanese and several Japanese dialects. Major typological differences observed in these varieties of pitch-accent systems will be discussed before concluding the paper.

\section{A Sketch of Typology of Lexical Suprasegmentals}

Suprasegmental, in the narrow sense to be adopted in this paper, refers solely to pitch phenomena over units of segmental combination such as the syllable. It can be further distinguished from intonation by the label 'lexical suprasegmental'. This deliberate separation between the sentence and the word is necessary for understanding suprasegmental phonology in its own right, free from potential reshaping of melody or added features introduced by discourse emphasis and contrast under pragmatic conditions. The treatment does not imply any autonomy in these domains. On the contrary, it is precisely the potential influence from discourse factors at the higher level that warrants the measures to be 
4 A Typological Study of Tonal Systems of Japanese and Prinmi:

taken. Now that the meaning of 'suprasegmental' has been clarified, it will be used as a synonym to 'lexical suprasegmental' below.

Some linguists would argue that tones conditioned by phonationregister, typically found in Khmer languages, should also be considered in the typology of lexical suprasegmentals (Alexis Michaud, personal communication). As the scope of this paper does not allow detailed discussion of all attested types of suprasegmentals, the brief discussion in this section will thus focus on stress-accent, pitch-accent, and tone, as exemplified by English, Japanese, and Mandarin, respectively. Table 1 displays some crucial characteristics of the suprasegmental system in these languages; all of them have been partially discussed in McCawley (1968: 135-137), Beckman (1986: 27-44), Donohue (1997), and Hulst (1999). Acoustic cues pertain to phonetic realization of the particular type of suprasegmental. Stress-accent is a combination of pitch and other elements such as intensity. The next two are phonological characteristics: weight sensitivity concerns components of the syllable; prosodic domain specifies the basic unit where the suprasegmental operates. Functional types of suprasegmental contrast include grammatical distinction and lexical distinction. The former differentiates grammatical meanings like word classes, while the latter contrasts unrelated (i.e., non-derived) meanings of content words. In different types of suprasegmental organization, the contrast in a system may be syntagmatic (the suprasegmental being interdependent with pitches of surrounding syllables in the basic domain) or paradigmatic (the suprasegmental being independent in the basic domain). Shaded areas in the table indicate common features shared between any two languages.

As can be seen from Table 1, pitch-accent languages share a number of characteristics with tone languages and stress-accent languages, but the latter two have little in common. Given the shared features, it is not surprising that Beckman (1986) groups Japanese with English together into accent languages, while Clark (1986) 
regards Japanese as a tone language (cf., also Hulst 1999: 80-82, among others).

Table 1. Salient Characteristics of the Suprasegmental Systems in English, Japanese, and Mandarin

\begin{tabular}{c|c|c|c}
\hline \hline & $\begin{array}{c}\text { English } \\
\text { (stress-accent) }\end{array}$ & $\begin{array}{c}\text { Japanese } \\
\text { (pitch-accent) }\end{array}$ & $\begin{array}{c}\text { Mandarin } \\
\text { (tone) }\end{array}$ \\
\hline $\begin{array}{c}\text { Acoustic cue } \\
\text { Weight sensitivity }\end{array}$ & Pitch, intensity & Pitch & Pitch \\
Prosodic domain & Word & No & No \\
Functional type & Grammatical & Mainly Lexical & Syllable \\
Contrast manner & Syntagmatic & Syntagmatic & Paradigmatic \\
\hline \hline
\end{tabular}

If we formulate the two phonological features 'weight sensitivity' and 'prosodic domain' in terms of the parameters [Weight-sensitive], [Syllable-base], and [Word-base] — each with a binary value, a typological tree of suprasegmentals, in part, can be outlined as follows:

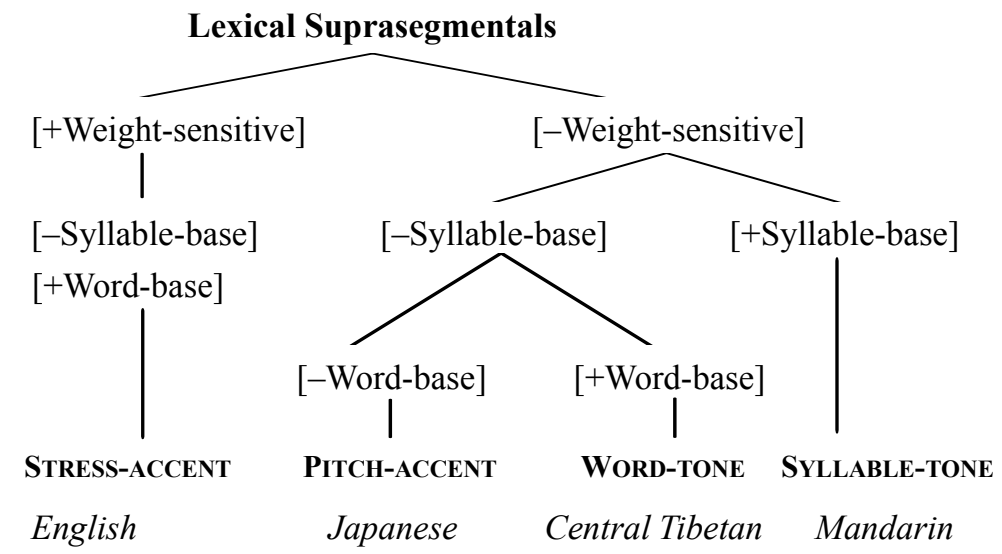

Figure 1. A Sketch of the Typological Tree of Lexical Suprasegmentals 
6 A Typological Study of Tonal Systems of Japanese and Prinmi:

It should be stressed again that the illustration sketched in Figure 1 does not provide a comprehensive typology of lexical suprasegmentals. Under the working of the set of parameters, a new suprasegmental system, the word-tone system, has emerged. Together with the syllable-tone system, the pitch-accent system, the three represent three prototypes of tonal systems (Ding 2001, 2005). Prime examples of the word-tone systems can be found in Central Tibetan, of which Lhasa Tibetan is the best known variety (cf., Mazaudon 1977). Duanmu's (1992) analysis of Lhasa and other dialects of Central Tibetan indicates that Central Tibetan is a word-tone language (although he does not use this term). Other identified word-tone languages include Wu such as Shanghai (Zee 2003, Duanmu 1992), Tamang (a Tibeto-Burman language of Nepal, cf., Mazaudon 1973, 1977) and Mende (an African language, cf., Heine \& Nurse 2000).

As shown in Figure 1, the prosodic domain, which underpins the suprasegmental system, functions as the distinct feature that separates these three kinds of tonal systems. Based on the syllable and on the word respectively, the prosodic domain in syllable-tone and word-tone languages is less abstract than the one in pitch-accent languages. While the underlying prosodic domain of the pitch-accent system is always larger than the syllable, it does not necessarily coincide with the word. This underlying prosodic domain, formulated with [-Syllable-base] and [-Word-base], is independent of the syllable and of the word. In general, for the underlying prosodic domain to be effective, it should match onto a word of at least two syllables/moras; the domain may be equal to the word, or it can be larger or smaller than the word.

In his typological study of tone in New Guinean languages, Donohue (1997: 352) has observed that the prosodic domain is vital for identifying different tonal systems. This observation can be elaborated to illustrate the organizational difference between the syllable-tone, word-tone, and pitch-accent systems. Let us look at 
the possible tonal patterns of three hypothetical languages, all with a simple suprasegmental contrast in terms of $\mathrm{H}$ and $\mathrm{L}$ :

Language $\mathrm{X}$ has a syllable-tone system. The tones $\mathrm{H}$ and $\mathrm{L}$ contrast with each other directly in monosyllabic words. In disyllabic words the maximum number of tonal combination is four (2x2): H-H, L-H, H-L, and L-L. In trisyllabic words the number rises to eight $(2 \times 2 \times 2)$ : H-H-H, L-H-H, H-L-H, L-L-H ... and L-L-L.

Language $\mathrm{Y}$ has a word-tone system with two tonal categories: HL and LH. The tones are realized as falling and rising respectively on monosyllabic words, but as $\mathrm{H}-\mathrm{L}$ and $\mathrm{L}-\mathrm{H}$ in disyllabic words. In trisyllabic words the two contrast as H-H-L versus L-L-H. There is no other tonal pattern.

Language $\mathrm{Z}$ has a pitch-accent system in which monosyllabic words can bear only the $\mathrm{H}$ tone; the $\mathrm{L}$ tone does not contrast directly with the $\mathrm{H}$ tone. But in longer words more tonal patterns emerge, as the $\mathrm{H}$ tone changes its position in the word. Disyllabic words have the patterns $\mathrm{H}-\mathrm{L}$ and $\mathrm{L}-\mathrm{H}$, whereas the exhaustive patterns for trisyllabic words are: H-L-L, L-H-L, and L-L-H.

The organization of suprasegmentals in the hypothetical languages is rather straightforward. Given the number of existent tonemes $(n)$ and the number of syllables in a word $(k)$, we can generate all the possible tonal patterns in a polysyllabic word $(t)$ for a syllable-tone language with the formula: $t=n^{k}$. The number of tonal contrast in word-tone languages remains constant, regardless of how long the word may be, i.e., $t=n$. This follows from the fact that what counts in word-tone languages is the word, not the syllable. Finally, in pitch-accent languages the number of possible suprasegmental contrast associated with the length of words can be formulated as: $t=k$. The more syllables a word has, the more 
8 A Typological Study of Tonal Systems of Japanese and Prinmi:

positions are available for placing the $\mathrm{H}$ tone varyingly to produce different patterns.

In principle, the organizational difference between these three kinds of tonal systems can be captured in the three algorithms, as noted by Odden (1995: 467-468) when illustrating dissimilar properties between (syllable-)tone and pitch-accent languages with the number of possible tonal contrasts in each of them. In reality, however, other factors must be taken into account. For instance, the feature of $\mathrm{H}$ tone spreading is often present in pitch-accent languages (as we will see later), which can increase the total number of possible tonal patterns. Depending on the details of the spreading specification, the algorithm for pitch-accent languages may be $t=k+1$ (as in standard Japanese) or $t=2 k+1$ (as in Prinmi).

\section{Defining the Pitch-accent System}

The term 'accent' is generally taken as a fall in pitch from high to low (cf., e.g., Shibatani 1990: 159, or more recently Akamatsu 1997: 180). This is essentially a phonetic attribute. The accent effect, at best, can only be regarded as a superficial trait of pitch-accent languages. It should not be considered as the distinctive feature of pitch-accent system. While the accent effect of pitch fall is often found in the suprasegmental patterns of pitch-accent languages, it is not obligatory for every single pattern (e.g., the so-called 'unaccented' pattern in Japanese). A definition of pitch-accent based on accent is unrevealing; indeed, what can be defined is the 'system of pitch-accent', not 'pitch-accent' per se.

Let us take a look at the overall suprasegmental system of standard Japanese, which is based on Tokyo (cf., Hirayama 1960): 
Table 2. Tonal Patterns of Standard Japanese (Tokyo)

\begin{tabular}{ccccc}
\hline \hline Type & 1-mora & 2-mora & 3-mora & 4-mora \\
\hline 0 & H & L-H & L-H-H & L-H-H-H \\
\hline 1 & H & H-L & H-L-L & H-L-L-L \\
\hline 2 & & L-H & L-H-L & L-H-L-L \\
\hline 3 & & & L-H-H & L-H-H-L \\
\hline 4 & & & L-H-H-H \\
\hline$\vdots$ & & & \\
n & & & & \\
\hline \hline
\end{tabular}

Since the size of the underlying domain is not fixed in standard Japanese, the number of types is open, ranging from Type- 0 to Type-n in the table. Type- 0 is usually regarded as 'unaccented', for the pattern does not have a pitch fall. It will be addressed later in Section 5.1. In all other types, the number in the type name signifies the locus of the $\mathrm{H}$ tone (rendered in bold in the table). Notice that the $\mathrm{H}$ tone, serving as a marked tone, is placed consecutively on a different position to generate different tonal patterns. Moreover, the marked $\mathrm{H}$ tone spreads leftward up to the second mora; other moras receive the default $\mathrm{L}$ tone.

Our discussion thus far indicates that pitch-accent languages like Japanese are characterized by:

(a) an underlying prosodic domain independent from both the syllable and the word;

(b) tonal patterns composed of a marked $\mathrm{H}$ tone and a default $\mathrm{L}$ tone (the two tones usually do not contrast directly in monosyllabic words);

(c) creating tonal patterns through the varying placement of the marked tone in the underlying domain; and

(d) a possible spreading of the marked tone.

Based on these properties, the pitch-accent system can be 
defined phonologically as follows, slightly modified from Ding (2001: 62):

A language possesses a PITCH-ACCENT SYSTEM if, and only if, its lexical tonal patterns are generated by placing a marked tone on the first, the second, the third, ..., and the $n^{\text {th }}$ position, respectively (or in the opposite order), in an underlying domain, independent of the word and the syllable, of $n$ moras/syllables (where $n \geq 2$ ), irrespective of the syllable weight.

The definition highlights the unique organization of a pitchaccent system with an emphasis on the sequential placement of the marked tone in the underlying domain. The notion of such an underlying domain for the pitch-accent system is somewhat similar to what McCawley (1968: 137-138) calls MINOR PHRASE, but he does not clarify its relation with the word (be it morphological or phonological). The tone-bearing unit (the carrier of suprasegmentals) can be either the syllable or the mora, subject to language-specific configuration.

Pitch-accent systems in different languages, or even between dialects of a language, may vary with regard to the length of the abstract domain, but it should have two syllables/moras as minimum. Although little is understood about the diachronic development of pitch-accent systems, I conjecture that the length of the underlying domain could play a significant role in this. A pitch-accent system with an underlying domain of two units can be considered to be at a developing stage, which could be analyzed as a word-tone system or even as a syllable-tone system, as discussed by Donohue (1997). In order to manifest the unique tonal patterns generated through a consecutive placement of the marked tone in the underlying domain, a full-fledged pitch-accent system will necessarily develop a domain longer than two units.

There are two reasons for specifying that the pitch-accent system 
is insensitive to the syllable weight. First, it clarifies that the possible locus of the marked tone is not constrained by any phonological factors such as the syllable weight. Secondly, it distinguishes the pitch-accent system from the metrical-accent system, on which the syllable weight impinges significantly. The 'accent' in metrical-accent languages such as Ainu is predictable in accordance with metrical rules (cf., Refsing 1986: 73-74, although she has applied the label 'pitch-accent' to Ainu; cf., also Hulst \& Smith 1988 for their discussion of Classical Greek as a metrical-accent language).

This refined definition of pitch-accent system, as will be shown in Section 5, is applicable to a variety of Japanese dialects. Other languages whose suprasegmental system can be identified as pitch-accent under this definition include Prinmi (see Ding 2001 for details) and Somali (a Cushitic language of Africa, cf., Saeed 1999).

\section{The Pitch-accent System in Prinmi}

Prinmi (or Pumi) is a Tibeto-Burman language spoken by the Pumi as well as by some groups officially classified as Tibetan in northwestern Yunnan and southwestern Sichuan in China. Ding (1998: 46-84) sets out the suprasegmental phonology of Prinmi in full detail, based on the Niuwozi dialect in Ninglang County, Yunnan. As analyzed in Ding $(2001,2003 a)$ and as will be shown below, Prinmi achieves lexical contrast through changing the location of a high tone in an underlying domain of a quadrisyllable. A preliminary dialectal study of the suprasegmental system of Prinmi, which covers over 10 localities in Lanping County, Yulong County, and Ninglang County (Ding 2003b), confirms that Prinmi, as a whole, possesses a pitch-accent system. Although words from different dialects may not always bear the same tonal category, variation in the pitch-accent system between the known dialects of 
12 A Typological Study of Tonal Systems of Japanese and Prinmi:

Prinmi appears to be marginal.

Since the descriptive framework adopted by Chinese linguists is modeled on Mandarin, earlier works on Prinmi hold the assumption that Prinmi is a (syllable-)tone language, but with rampant 'tone sandhi' (Lu 1983: 15-16, 19-20; Fu 1998: 18-20). Matisoff (1997: 206-209) describes the suprasegmentals of Dayang Prinmi (spoken in Lanping County) in terms of two 'tones'. An accidental finding from the dialectal study in Ding (2003b) is that linguistic attrition has made its way into the suprasegmentals of some younger speakers' Prinmi; the native speaker who worked with Matisoff comments that she is no longer certain about the distinction between $m \tilde{e}^{F}$ 'hair' and $m \tilde{e}^{H}$ 'name', although she still recognizes other pairs of words which contrast minimally between these two tonal categories. This informant is an otherwise competent speaker of Prinmi, although she has seldom spoken the language (certainly not on a daily basis) since living in Kunming in the early 1990s.

According to $\mathrm{Lu}$ (2001: 108), a distinctive feature between 'Southern' Prinmi and 'Northern' Prinmi can be found in their suprasegmental systems: the former has two tones and the latter has three. ${ }^{2}$ In particular, Niuwozi (spoken in Xinyingpan, Ninglang, Yunnan) would have only two tones, being a dialect of 'Southern' Prinmi (cf., Lu 2001: 97). Nonetheless, all Prinmi dialects I have come into contact make a three-way suprasegmental contrast in monosyllabic words (an account of the disagreement in descriptions of Prinmi suprasegmentals will be discussed below). For instance, consider the following sets of examples from Niuwozi and their tonal patterns in citation form and in connected speech (surface

2 Both $\mathrm{Lu}$ (1983) and $\mathrm{Lu}$ (2001) are based on findings from field research conducted by Lu Shaozun and Luo Bingfen in a variety of localities in Sichuan and Yunnan (excluding Lanping) in 1956-1957, and by Lu Shaozun and Sun Hongkai in Lanping (Yunnan) in 1964 and in Muli (Sichuan) in 1980 (Lu 2001: 607). They feature an identical description of the suprasegmentals of Prinmi. 
tones are indicated after a syllable: $\mathrm{H}=$ high level, $\mathrm{F}=$ falling, $\mathrm{R}=$ rising, and $\mathrm{L}=$ low level):
High
Falling
Rising
(a) $\int i^{\mathrm{H}}$ 'hundred'
$\int i^{\mathrm{F}}$ 'louse'
$\int i^{\mathrm{R}}$ 'new'
(citation)
$\int i^{\mathrm{H}} g e^{\mathrm{H}}$
$\int i^{\mathrm{H}} g e^{\mathrm{L}}$
$\int i^{\mathrm{L}} g e^{\mathrm{H}}$
(speech)
(b) $b j \tilde{\varepsilon}^{\mathrm{H}}$ 'busy'
bj $\tilde{\varepsilon}^{\mathrm{F}}$ 'urine'
bj $\tilde{\varepsilon}^{\mathrm{R}}$ 'to fly'
(citation)
$b j \tilde{\varepsilon}^{\mathrm{H}} g e^{\mathrm{H}}$
bj $\tilde{\varepsilon}^{\mathrm{H}} g e^{\mathrm{L}}$
$b j \tilde{\varepsilon}^{\mathrm{L}} g e^{\mathrm{H}}$
(c) $l_{3 j} \mathrm{H}$,
$l_{3 j}{ }^{\mathrm{F}}$ 'heavy'
$l_{3 j}{ }^{\mathrm{R}}$
(speech)
$l_{3 j}{ }^{\mathrm{H}} g e^{\mathrm{H}}$
$l_{3 j}{ }^{\mathrm{H}} g e^{\mathrm{L}}$
'to seed'
(citation)
$l_{3 j}{ }^{\mathrm{L}} g e^{\mathrm{H}}$
(speech)

As is typical in Sino-Tibetan languages, Prinmi is predominantly monosyllabic at the morpheme level. Regardless of syllable weight, monosyllabic words may bear a high tone, a falling tone, or a rising tone. These are merely surface tones, not tonemes as found in syllable-tone languages. The suprasegmental contrast between the high tone and the falling tone is mostly neutralized in the citation form. However, the intended contrast is manifest when monosyllabic words are followed by clitics such as /ge/ (a topic-marker) in connected speech, where all the surface tones effectively contrast in terms of two pitches: high vs. low.

With a wealth of compounds, the most common suprasegmental patterns in words/clitic groups, ranging from monosyllables to quadrisyllables, are those presented in Table 3. The table attempts to display the regularity of the tonal patterns as the number of syllables in words (either the morphological or phonological word) increases. Treating $\mathrm{H}$ as the marked tone, we can analyze these suprasegmental patterns with two parameters, which specify the locus of the $\mathrm{H}$ tone and whether it spreads progressively to the adjacent syllable. 
14 A Typological Study of Tonal Systems of Japanese and Prinmi:

Table 3. The Most Common Suprasegmental Patterns in Niuwozi Prinmi

\begin{tabular}{|c|c|c|c|}
\hline Monosyllable & $\begin{array}{c}\text { Disyllable } \\
\end{array}$ & Trisyllable & Quadrisyllable \\
\hline $\begin{array}{c}b i^{F} \\
\text { 'honey’ }\end{array}$ & $\begin{array}{c}b \dot{t}^{H} g e^{\mathrm{L}} \\
\text { 'as for } \\
\text { honey' }\end{array}$ & $\begin{array}{l}b_{i}^{H} b^{d} \tilde{o}^{L} b^{d} \tilde{o}^{L} \\
\text { 'roasted flour with } \\
\text { honey' }\end{array}$ & $\begin{array}{l}b i^{H} b^{\wedge} \tilde{o}^{L} b^{\Lambda} \tilde{o}^{L} g e^{\mathrm{L}} \\
\text { 'as for roasted flour with } \\
\text { honey' }\end{array}$ \\
\hline $\begin{array}{l}b \dot{t}^{H} \\
\text { 'sun' }\end{array}$ & $\begin{array}{l}b i^{H} g e^{\mathrm{H}} \\
\text { 'as for sun' }\end{array}$ & $\begin{array}{c}b i^{H}{ }_{d i}{ }^{H} \cdot d u^{L} \\
\text { 'sunflower stem' }\end{array}$ & $\begin{array}{c}b i^{H_{1}} d i^{H} p p^{L} t s i^{L} \\
\text { 'sunflower' }\end{array}$ \\
\hline $\begin{array}{l}t \int^{\prime} \hat{t}^{R} \\
\text { 'dog' }\end{array}$ & $\begin{array}{l}t \int^{\prime}{ }^{L}{ }^{L} m \tilde{e}^{H} \\
\text { 'dog hair' }\end{array}$ & $\begin{array}{l}t \int^{\top}{ }^{L}{ }^{L} n \tilde{l}^{H} d z j \tilde{\varepsilon}^{L} \\
\text { 'dog-nose group' }\end{array}$ & $\begin{array}{c}t \int^{\prime} \dot{t}^{L} n_{0} \tilde{l}^{H} d z j \tilde{\varepsilon}^{L} \quad . \partial^{L} \\
\text { 'dog-nose groups' }\end{array}$ \\
\hline & $\begin{array}{l}t \tilde{o}^{L} p u^{H} \\
\text { 'donkey' }\end{array}$ & $\begin{array}{l}t \tilde{o}^{L} p u^{H} k^{\prime} u^{H} \\
\text { 'donkey head' }\end{array}$ & $\begin{array}{c}t \tilde{o}^{L} p u^{H} m 3^{H} t e^{L} \\
\text { 'donkey tail' }\end{array}$ \\
\hline & $\begin{array}{l}d_{3 j} \tilde{o}^{L} d 3^{R}{ }^{R} \\
\text { 'buffalo' }\end{array}$ & $\begin{array}{l}d_{3 j} j^{L} d_{3} i^{L} k^{\prime} \boldsymbol{u}^{H} \\
\text { 'buffalo head' }\end{array}$ & $\begin{array}{l}d z j \tilde{o}^{L} d 3^{L} m_{3}{ }^{H} t e^{L} \\
\text { buffalo tail }\end{array}$ \\
\hline & $\begin{array}{l}. \partial_{t f j}{ }^{R} \\
\text { 'liquor' }\end{array}$ & $\begin{array}{l}. \partial^{L} t f j^{L} \int \tilde{o}^{H} \\
\text { 'clean liquor' }\end{array}$ & $\begin{array}{l}d \partial^{L} t j^{L} \int \tilde{o}^{H} g e^{\mathrm{H}} \\
\text { 'as for clean liquor' }\end{array}$ \\
\hline & & $\begin{array}{c}d \partial_{0}^{L} d \partial_{d a}^{L} \tilde{l}^{R} \\
\text { 'concentrate' }\end{array}$ & $\begin{array}{l}d \partial^{L}{ }_{a} \lambda \partial_{d}^{L} \tilde{l}^{L} \quad s i^{H} \\
\text { 'concentrated' }\end{array}$ \\
\hline
\end{tabular}

Table 4. Suprasegmental Categories of Niuwozi Prinmi

\begin{tabular}{llcccc}
\hline \hline \multicolumn{1}{c}{ Parameters } & Monosyllable & Disyllable & Trisyllable Quadrisyllable \\
\hline A & {$[1]$ [-spread] } & Falling & H-L & H-L-L & H-L-L-L \\
B & [1] [+spread] & High & H-H & H-H-L & H-H-L-L \\
C & [2] [-spread] & Rising & L-H & L-H-L & L-H-L-L \\
D & [2] [+spread] & & L-H & L-H-H & L-H-H-L \\
E & [3] [-spread] & & L-R & L-L-H & L-L-H-L \\
F & [3] [+spread] & & & L-L-H & L-L-H-H \\
G [4] [spread] & & & L-L-R & L-L-L-H \\
\hline \hline
\end{tabular}

The bracketed number in the first parameter designates the locus of the $\mathrm{H}$ tone in the quadrisyllabic domain, while the other parameter signifies whether the spreading of the $H$ tone is: 
obligatory ([+spread $])$, prohibited ([-spread $])$, or unspecified ([spread]). Ignoring the shaded rows for Categories B, D, and F for the time being, we can clearly see that the tonal patterns are generated simply by placing the $\mathrm{H}$ tone on the first, the second, the third, and the fourth syllables, respectively, in the underlying domain. The other three tonal categories in the remainder have the extra property of spreading the $\mathrm{H}$ tone to the next syllable, and they too are based on the varying position of the $\mathrm{H}$ tone in the underlying domain. By the definition provided in Section 3, we identify Prinmi as possessing a pitch-accent system.

Representative examples for words in each of the seven tonal categories include:

Category A, $\quad m \tilde{e}^{F}$ 'hair', $w_{3}{ }^{H} m i^{L}$ 'cow', $b i^{H}{ }^{H} j e^{L} d j e^{L}$ 'really thin', [1;-spread]: $\quad t_{53}{ }^{H}{ }_{3} i^{L} n \tilde{l}^{L} d_{3 j} \tilde{o}^{L}$ 'monkey-nose'

Category B, $\quad m \tilde{e}^{H}$ 'name', $m j e^{H} S t^{H}$ 'eyeball', $p^{\alpha}{ }^{\prime}{ }_{l}^{H} t j j e^{H} t j j e^{L}$

[1; +spread]: 'really white', $m \tilde{e}^{H}{ }_{t s}{ }^{\prime} O^{H}{ }_{d 3}{ }^{L} k a^{L}$ 'pelvis'

Category C, $\quad d^{R}$ 'sickle', $p j \tilde{\varepsilon}^{L} k w{ }^{H}{ }^{H}$ 'feral ox', $n j e^{L}$ tew ${ }^{H}$ tew ${ }^{L}$

[2;-spread]: 'really lonely', jo $\tilde{o}^{L} d z i^{H} p a^{L} p a^{L}$ 'bat'

Category D, $\quad b a^{L}{ }_{13 j}{ }^{\mathrm{H}}$ 'snake', $s e^{L} l e w^{H} b \tilde{o}^{H}$ 'pear tree',

[2; + spread]: $\quad g u^{L}{ }^{L} i^{H}{ }_{t a} H_{t s i}{ }^{L}$ 'middle finger'

Category E, $\quad k o^{L} j i^{R}$ 'crow', $m 3^{L}{ }_{t s i}{ }^{L} \cdot{ }^{2} \partial^{H}$ 'cat-skin',

[3;-spread]: $\quad \operatorname{tju}^{L}{ }_{t s i}{ }^{L}{ }_{n}{ }^{H}{ }^{H}{ }_{3} o^{L}$ 'hare-ear'

Category F, $\quad t u^{L} b^{\wedge} \tilde{o}^{L} b^{\wedge} \tilde{o}^{H}$ 'roasted barley flour mixed with oil',

[3; +spread]: $\quad k^{\prime} i^{L} b \tilde{o}^{L} t \int^{\prime} y e^{H} b \tilde{o}^{H}$ 'chicken pox'

Category G, $\quad t \hat{i}^{L} t^{\prime} o^{L} t^{\prime} o^{R}$ 'waterfall', $t a^{L} t s i^{L}{ }_{13}{ }^{L} k^{H}{ }^{H}$ 'finger bone' [4; spread]:

Having examined the general tonal patterns attested in Prinmi, we find the pitch-accent system rather transparent. Nonetheless, if we confined our investigation to simple words in this predominantly monosyllabic language, we could be misled into analyzing Prinmi as a syllable-tone language (cf., Ding 1999). As shown above, 
monosyllabic Prinmi words have a three-way contrast, with a high level tone, a falling tone, and a rising tone. One may question whether a contour tone such as falling and rising is allowed in pitch-accent languages. The answer is positive. This is found not only in Prinmi, but also in some Japanese dialects (cf., the discussion in Section 6). Perhaps more important than these unusual, but permitted, instances is the fact that no rule in the suprasegmental organization of pitch-accent system prevents a tone-bearing unit from taking a sequence of two level tones. When the (morphological) word is shorter than the underlying domain, different pitch-accent languages/dialects may react differently. In the case of Prinmi, a rising tone is accommodated when the $\mathrm{H}$ tone is specified at a position outside the (morphological) word. On the other hand, the extra level tone in the tonal category A, [1; -spread], is less fortunate. When the underlying domain matches onto a monosyllabic word, the low level tone, being a default tone in the underlying domain, cannot fully secure room in the syllable. As a result, most native speakers are unable to distinguish it from the tonal category $\mathrm{B},[1 ;+$ spread $]$, in the citation form of monosyllabic words. A neutralization of the two categories thus arises in this ineffective environment, which also largely accounts for the description of a two-tone system in Prinmi dialects spoken in Lanping.

That the underlying domain in the pitch-accent system of Prinmi is quadrisyllabic appears to be attributed to the typological profile of Prinmi. As a primarily monosyllabic language, Prinmi has few words longer than four syllables. Almost all quadrisyllabic native words are compounds, and many of them contain more than one underlying domain in their tonal organization. Prinmi is not unique in this regard. According to Inoue (1930: 99), Maizuru Japanese also displays a duo-domain pattern in compounds containing a numeral, e.g., $d a^{H} i^{L} i_{i}{ }^{H} c h i^{L}$ 'first', $j i^{H} u^{L}{ }_{-} s a^{H} n^{H}$ 'thirteen', and $s a^{H} n^{H} j i^{L} u^{L}{ }_{g} o^{H} e^{L} n^{L}$ 'thirty-five dollars'. The boundary of the 
underlying domains in these compounds coincides with the formative boundary indicated by the sign '_.'. Alternatively, the suprasegmentals of numeral compounds in Maizuru can be organized under one domain instead of two, e.g., $d a^{H} i^{L} i^{L} c h i^{L}$ 'first' and $j i^{H} u^{L}{ }_{-} s a^{L} n^{L}$ 'thirteen'. This kind of alternative is not available in Prinmi, though.

As an illustration of multi-domain words in Prinmi, consider the following quadrisyllabic and octosyllabic compounds ('+': boundary of underlying domains; ' _': boundary of formatives of compounds):

$$
\begin{aligned}
& \text { [3; spread }]+[1 ;+ \text { spread }] \\
& { }_{S 3}{ }^{L}{ }_{3}{ }^{R} \quad-{ }_{o} j e^{H} m_{o} j e^{H} \quad \text { 'fights and wars' } \\
& {[1 ; \text { +spread }]+[1 ; \text {-spread }]+[1 ;- \text { spread }]} \\
& \left\{\left[\left(k^{d}{ }^{\prime}{ }^{H} \_d u^{H}\right) \_13^{L} k a^{L}\right] \_\left[\left(1 \partial^{H} \_t \int^{\prime} y e^{L}\right) \_13^{H} k a^{L}\right]\right\} \text { 'tibia' }
\end{aligned}
$$

Ding (2001: 70) notes that if a Prinmi word consists of more than one underlying domain, the boundary of these domains must coincide with the morphological boundary of the word (i.e., the boundary between formatives in the case of compounds). This can be referred to as the Condition of Boundary Coincidence, which predicts that only morphologically complex words may contain multiple underlying domains. Returning to the examples, it is unacceptable to break down the pattern in (2) as $\mathrm{L}-\mathrm{R}+\mathrm{H}+\mathrm{H}$, for it would violate the Condition of Boundary Coincidence. Note that a rising tone occurs in the second syllable of the compound, since the first formative contains only two syllables, but the $\mathrm{H}$ tone is designated on the third syllable in the underlying domain. More complexly, the octosyllabic compound in (3) is built on three levels of compounding, as indicated by the different bracketings. This longest attested word in Prinmi consists of three underlying domains, in that manner of composition as analyzed in (3). It also shows that the boundary between several underlying domains in a compound, if 
18 A Typological Study of Tonal Systems of Japanese and Prinmi:

any, is not predicted by the morphological boundary.

\section{The Pitch-accent Systems in Japanese}

Having investigated the pitch-accent system in Prinmi, we now focus on suprasegmentals of Japanese. It is well-known in Japanese dialectology that the suprasegmentals of Japanese dialects represent a prominent aspect of regional variation. According to suprasegmental characteristics, Shibatani (1990: 181) identifies three primary groups: (a) the $\mathrm{H}$ melody group, represented by Tokyo Japanese, (b) the $\mathrm{H}$ and $\mathrm{L}$ melody group, represented by Osaka Japanese, and (c) the L melody group, represented by Kagoshima Japanese. An alternative approach to the pitch-accent systems of Japanese dialects will be presented in this section, showing that it is possible to have a uniform pitch-accent analysis with $\mathrm{H}$ as the marked tone in conjunction with dialect-specific details such as the manner of H-tone spreading. The dialects to be examined are: Tokyo, Kyoto, Nagoya, Narada, Shizukuishimachi, and Kagoshima.

A brief note on the tone-bearing unit in Japanese is in order here. While there is a consensus as to Japanese being a mora-counting language, it is controversial whether the tone-bearing unit is mora (cf., Akamatsu 1997: 177) or syllable (cf., McCawley 1968: 131-134; Shibatani 1990: 158-160). Since the dialectal data used in the paper are based on Japanese sources where the mora is taken as the basic unit for both counting and tone-bearing, I will follow this practice in the presentation of Japanese data.

\subsection{Tokyo (Standard Japanese)}

Selected as the basis for standard Japanese, Tokyo represents the best known variety of Japanese. Adopting the two-parameter approach used earlier in the analysis of Prinmi suprasegmentals, we 
can present the pitch-accent system of Tokyo as in Table 5. Since the same leftward spreading of the $\mathrm{H}$ tone applies to all cases, an explicit specification of the spreading parameter would be redundant. Thus only the parameter for the locus of the $\mathrm{H}$ tone is provided in the table.

The tonal pattern labeled as 'Type-0', as noted earlier, is unique among all the patterns. While it is possible to describe this pattern in terms of absence of accent (effect), such a treatment suffers some

Table 5. An Analysis of the Pitch-accent System of Tokyo Japanese

\begin{tabular}{cccccc}
\hline \hline \multicolumn{2}{c}{ Type Parameter } & 1-mora & 2-mora & 3-mora & 4-mora \\
\hline 0 & {$[\mathrm{n}]$} & $\mathbf{H}$ & L-H & L-H-H & L-H-H-H \\
\hline 1 & {$[1]$} & $\mathbf{H}$ & H-L & H-L-L & H-L-L-L \\
\hline 2 & {$[2]$} & & L-H & L-H-L & L-H-L-L \\
\hline 3 & {$[3]$} & & & L-H-H & L-H-H-L \\
\hline 4 & {$[4]$} & & & & L-H-H-H \\
\hline$\vdots$ & & & & & \\
\hline \hline
\end{tabular}

minor drawbacks in perception. In syllable-tone languages such as Mandarin, all content monosyllabic words bear lexical tones; toneless syllables are resulted from grammaticalization or morphonological processes. In any event, they represent a minor group. Similarly, stress-accent languages such as English confine stressless words to closed classes like articles and prepositions (cf., Hulst 1999: 6). Japanese, as a pitch-accent language, would stand out as odd in having a large number of content words that are 'unaccented'.

If we start from the other edge of the underlying domain when counting the locus of the $\mathrm{H}$ tone, we find that the $\mathrm{H}$ tone in Type- 0 always occupies the rightmost position in the underlying domain; what varies is the distance from the marked $\mathrm{H}$ tone to the left edge of the domain, as the domain increases its length. Under this 
20 A Typological Study of Tonal Systems of Japanese and Prinmi:

approach, the Type-0 pattern differs from the other patterns in having a variable, rather than constant, number in the parameter for the locus of the $\mathrm{H}$ tone. The value of the variable in [n] is instantiated by the number of moras in a particular domain. Consequently, the $\mathrm{H}$ tone always appears on the final mora of a phonological word, and then spreads leftward until the second mora, as in other patterns.

Adapted from Uwano (1977), the following are examples of words in these tonal categories of Tokyo (letter repetition indicates lengthening in Japanese):

Category [n]: $e$ 'handle', kaze 'wind', sakura 'cherry', niwatori 'chicken';

Category [1]: e 'picture', saru 'monkey', kabuto 'helmet', koomori 'bat';

Category [2]: yama 'mountain', kokoro 'heart', asagao 'morning glory';

Category [3]: kagami 'mirror', aozora 'blue sky'; and

Category [4]: nokogiri 'saw', otooto 'younger brother'.

Uwano (1977: 284) notes that many natives of Tokyo have an additional pattern of L-H-H for kokoro 'heart', which suggests that the word has a variant tonal category, i.e., Category [3]. Similarly, nokogiri 'saw' has two possible patterns in Tokyo: L-H-H-L and L-H-H-H, which correspond to Category [3] and Category [4] respectively. Uwano has assigned the word to Category [4], but Takashi Kato (personal communication) comments that in his idiolect of Tokyo the word belongs to Category [3] only. Such variations of tonal patterns/categories on a word between speakers of one dialect or within a single speaker are not uncommon in pitch-accent languages; they have been observed in Prinmi as well. 


\subsection{Kyoto}

Dialects of the Kyoto-Osaka region have a slightly more complicated pitch-accent system than the one in Tokyo. In Kyoto it is necessary to indicate whether the $\mathrm{H}$ tone spreads or not, in addition to specification of the position of the $\mathrm{H}$ tone. With these two parameters, the pitch-accent system of Kyoto can be analyzed as follows:

Table 6. An Analysis of the Pitch-accent System of Kyoto Japanese, Based on Description from Hirayama (1960: 90-91)

\begin{tabular}{lcccc}
\hline \multicolumn{1}{c}{ Parameters } & 2-mora & 3-mora & 4-mora & 5-mora \\
\hline [n] [+spread] & H-H & H-H-H & H-H-H-H & H-H-H-H-H \\
[n] [-spread] & L-H & L-L-H & L-L-L-H & L-L-L-L-H \\
[1] [spread] & H-L & H-L-L & H-L-L-L & H-L-L-L-L \\
\hline [2] [+spread] & & H-H-L & H-H-L-L & H-H-L-L-L \\
[2] [-spread] & L-F & L-H-L & L-H-L-L & L-H-L-L-L \\
\hline [3] [+spread] & & & H-H-H-L & H-H-H-L-L \\
[3] [-spread] & & L-L-F & L-L-H-L & L-L-H-L-L \\
\hline & & & & \\
\hline \hline
\end{tabular}

As in Tokyo, spreading of the $\mathrm{H}$ tone proceeds leftward. However, unlike the restricted spreading in Tokyo, the $\mathrm{H}$ tone in Kyoto spreads straight to the initial mora in the underlying domain if spreading occurs. While Tokyo always spreads the $\mathrm{H}$ tone, Kyoto has a choice between spreading and non-spreading. This gives rise to a higher number of possible tonal patterns in Kyoto. The spreading is irrelevant when the $\mathrm{H}$ tone is placed on the initial mora, for there is no room for spreading to take place. Note that the $\mathrm{H}$ tone is present in all patterns, including the two specified as [n], where the $\mathrm{H}$ tone is counted from the right edge of the underlying domain.

Unlike that in Tokyo, Kyoto appears intolerant of suprasegmental neutralization. To keep tonal categories distinct from that 
of $[\mathrm{n} ;+$ spread], some patterns in defective domains are left unused, e.g., $[2 ;+$ spread $]$ is not used for two-mora words and $[3 ;+$ spread $]$ is avoided for three-mora words. On the other hand, a new surface tone may emerge from the ineffective environments. For instance, when the tonal category $[2 ;-$ spread] is applied to two-mora words or the category $[3 ;-$ spread] to three-mora words, a falling tone (F) occurs on the final mora of the word so as to maintain the tonal contrast with those patterns under the category [n; -spread], as shown in Table 6.

Note that one-mora words are absent from Table 6, because vowel lengthening, as a dialectal feature, has rendered corresponding one-mora words in Tokyo as two-mora words in Kyoto-Osaka dialects (cf., Shibatani 1990: 198). The vowel lengthening has also led to the marked tone to be placed between the second and the $n$th mora of the underlying domain, which suggests that the marked tone is placed consecutively from the right rather than from the left. Suprasegmentally, Kyoto does not regard the nasal mora, the vowel-lengthening mora, or the consonant-lengthening mora as incompatible with the marked tone, in contrast to what happens in Tokyo (as noted in Akamatsu 1997: 197-198). In fact, the indiscrimination on mora types is common to Kyoto-Osaka dialects (cf., Shibatani 1990: 160). Inoue (1930: 94-96) also discusses this property in the suprasegmentals of Maizuru, spoken in Kyoto prefecture.

The following gives some examples for each of the seven tonal categories of Tokyo listed in Table 6:
Category
ee 'handle', mizu 'water', kodomo 'child',
[n; +spread]: nichibotsu 'sunset';
Category ee 'picture', ito 'thread', mukashi 'the past',
[n; -spread]: maitoshi 'every year', shinbun 'newspaper';
Category haa 'leaf', kawa 'river', asahi 'morning [1; spread]: sun', fujiyama 'Mount Fuji'; 
Category

onna 'female', kanashii 'sorrowful';

$[2 ;+$ spread]:

Category saru 'monkey', kabuto 'helmet', bidanshi

[2;-spread]: 'handsome man';

Category kagaribi 'campfire', ureigao 'sad face'; and [3; +spread]:

Category noppo 'a lanky person', irogami 'colored $[3 ;-$ spread $]$ : paper', sotogamae 'outward structure'.

\subsection{Nagoya}

Nagoya is suprasegmentally closer to Tokyo than to Kyoto. Leftward spreading occurs in all tonal patterns (in principle), but more restrictively: the spreading ceases at the third mora, not affecting the first two moras. Therefore, the spreading parameter can be spared in the analysis of the pitch-accent system of Nagoya. The marked $\mathrm{H}$ tone, however, always 'diffuses' to the immediately preceding mora when its locus is on one of the special moras: nasal mora, vowel-lengthening mora, or consonant-lengthening mora (Uwano 1977: 291). Being different in nature from H-tone spreading, the 'diffusion' disregards the prohibition of affecting the first two moras in the underlying domain.

Table 7. An Analysis of the Pitch-accent System of Nagoya Japanese, Based on Description in Uwano (1977: 290)

\begin{tabular}{cccccc}
\hline \hline Parameter & 1-mora & 2-mora & 3-mora & 4-mora & 5-mora \\
\hline$[\mathrm{n}]$ & $\mathbf{H}$ & L-H & L-L-H & L-L-H-H & L-L-H-H-H \\
\hline$[1]$ & $\mathbf{H}$ & H-L & H-L-L & H-L-L-L & H-L-L-L-L \\
\hline$[2]$ & & L-H & L-H-L & L-H-L-L & L-H-L-L-L \\
\hline$[3]$ & & & L-L-H & L-L-H-L & L-L-H-L-L \\
\hline$[4]$ & & & & L-L-H-H & L-L-H-H-L \\
\hline$\vdots$ & & & & & \\
\hline \hline
\end{tabular}


24 A Typological Study of Tonal Systems of Japanese and Prinmi:

Some examples of words in these tonal categories of Nagoya are:

Category [n]: $e$ 'handle', kaze 'wind', sakura 'cherry', niwatori 'chicken';

Category [1]: e 'picture', saru 'monkey', kabuto 'helmet', koomori 'bat';

Category [2]: yama 'mountain', kokoro 'heart', asagao 'morning glory';

Category [3]: kagami 'mirror', aozora 'blue sky'; and Category [4]: nokogiri 'saw'.

Notice that spreading does not take place in the categories with the parameters [1], [2], and [3]. This is because the leftward spreading may not affect the first two moras in the underlying domain. A similar situation is also observed in Tokyo for categories with the parameters [1] and [2]. The spreading only comes into effect when the $\mathrm{H}$ tone is placed after the third mora in the underlying domain.

\subsection{Narada}

Spoken in Yamanashi, a prefecture west of Tokyo, Narada has developed a rather unusual kind of pitch-accent system. Under the notion of 'one-word-one-pitch-fall', Narada would not be considered as a pitch-accent language. In this dialect, it is possible to have two instances of pitch fall in a word, with a tonal pattern like H-L-L-H-L. However, after a careful examination of the overall tonal patterns of the dialect, it is clear that the organization of suprasegmentals in Narada follows the same fundamental principle found in other pitch-accent systems - the change of locus of the marked tone generates a new tonal category. A pitch-accent analysis of the suprasegmental system of Narada is proposed in Table 8 . 
Table 8. An Analysis of the Pitch-accent System of Narada Japanese, Based on Description in Uwano (1977: 293)

\begin{tabular}{|c|c|c|c|c|c|}
\hline Parameter & 1-mora & 2-mora & 3-mora & 4-mora & 5-mora \\
\hline [1] & $\mathbf{H}$ & H-L & H-L-L & H-L-L-L & H-L-L-L-L \\
\hline [2] & H & L-H & L-H-L & L-H-L-L & L-H-L-L-L \\
\hline [3] & & H-L & H-L-H & H-L-H-L & H-L-H-L-L \\
\hline [4] & & & H-L-L & H-L-L-H & H-L-L-H-L \\
\hline [5] & & & & H-L-L-L & H-L-L-L-H \\
\hline
\end{tabular}

As shown in the Table, the placement of the marked $\mathrm{H}$ tone (rendered in bold) in the underlying domain determines the shape of the pattern in every tonal category. Unlike the other three dialects discussed above, Narada only counts the location of the marked $\mathrm{H}$ tone from the left edge of the underlying domain. Furthermore, the $\mathrm{H}$ tone does not spread. Above all these differences is the peculiarity that a non-marked high tone occurs in the initial mora for categories with the parameters [3], [4], and [5], etc. To account for this, an insertion rule can be used: a high tone is assigned to the initial mora of a word, provided that it will not be adjacent to the marked $\mathrm{H}$ tone. As such, this rule applies only to tonal categories whose parameter is specified as [3], [4], and so forth.

The majority of Japanese dialects require a word to accommodate the $\mathrm{H}$ tone within its morphological domain, bar those categories counting from the right edge. However, Narada permits the marked $\mathrm{H}$ tone to be placed one mora outside the word. That is, the underlying domain applicable to a word does not necessarily coincide with the word in length; a shorter pattern such as H-L-L (after H-insertion) from the tonal category with the parameter [4] can occur on a three-mora word, e.g., $k a^{H} g a^{L} m i^{L}\left(g a^{H}\right)$ '(as for) mirror'. This is similar to the Prinmi situation which results in a rising surface tone.

Some examples of words in the tonal categories of Narada 
26 A Typological Study of Tonal Systems of Japanese and Prinmi:

include:

Category [1]: $e$ 'handle', kaze 'wind', sakura 'cherry', niwatori 'chicken';

Category [2]: e 'picture', saru 'monkey', kabuto 'helmet', koomori 'bat';

Category [3]: yama 'mountain', kokoro 'heart', asagao 'morning glory';

Category [4]: kagami 'mirror', aozora 'blue sky'; and Category [5]: nokogiri 'saw'.

\subsection{Shizukuishimachi}

Shizukuishimachi, spoken in Iwate prefecture in northeastern Honshu, has two subsystems of suprasegmentals: one for completed speech and the other for connected speech. The former refers to the kind of abbreviated utterances used as short answers to questions, e.g., "A picture." as a response to "What is this?". The two subsystems of pitch-accent in Shizukuishimachi, based on Uwano's (1977: 301) description, can be analyzed as follows:

Table 9. An Analysis of the Suprasegmentals of Completed Speech in Shizukuishimachi Japanese

\begin{tabular}{cccccc}
\hline \hline Parameters & 1-mora & 2-mora & 3-mora & 4-mora & 5-mora \\
\hline$[0]$ & L & L-L & L-L-L & L-L-L-L & L-L-L-L-L \\
\hline [1] [-spread] & Falling & H-L & H-L-L & H-L-L-L & H-L-L-L-L \\
\hline [2] [-spread] & L-F & L-H-L & L-H-L-L & L-H-L-L-L \\
\hline [3] [-spread] & & L-L-F & L-L-H-L & L-L-H-L-L \\
\hline [4] [-spread] & & & L-L-L-F & L-L-L-H-L \\
\hline$\vdots$ & & & & \\
\hline \hline
\end{tabular}


Table 10. An Analysis of the Suprasegmentals of Connected Speech in Shizukuishimachi Japanese

\begin{tabular}{cccccc}
\hline \hline Parameters & 1-mora & 2-mora & 3-mora & 4-mora & 5-mora \\
\hline$[0]$ & L & L-L & L-L-L & L-L-L-L & L-L-L-L-L \\
\hline$[1][+$ spread $]$ & H & H-H & H-H-H & H-H-H-H & H-H-H-H-H \\
\hline 2] [+spread $]$ & & L-H & L-H-H & L-H-H-H & L-H-H-H-H \\
\hline [3] [+spread $]$ & & & L-L-H & L-L-H-H & L-L-H-H-H \\
\hline [4] [+spread $]$ & & & & L-L-L-H & L-L-L-H-H \\
\hline$\vdots$ & & & & & \\
\hline \hline
\end{tabular}

Comparing the tonal patterns in completed speech with those in connected speech, it is obvious that the two diverge in regard to whether the $\mathrm{H}$ tone spreads or not. No spreading occurs in completed speech, but rightward spreading takes place in connected speech. An unusual (but not peculiar) property observed in the tonal patterns of Shizukuishimachi is the possibility of not having a marked $\mathrm{H}$ tone, as in the category [0]. Consequently, the pattern features only a low tone, a phenomenon observed also in Fujitsu of Western Kyushu in one of its two tonal categories by Wada (1962: 195) (cited in McCawley 1968: 193). This gives rise to an exceptional contrast in monomoraic words, where the low tone comes in direct opposition to the high tone (realized either as level or falling).

Note that a falling tone occurs in certain patterns in completed speech where the domain lacks a mora for the anticipated low tone. Omitting the spreading parameter (which is relevant to the speech type only), we may exemplify the tonal categories of Shizukuishimachi with the following words:

Category [0]: e 'handle', kaze 'wind', sakura 'cherry', tomodachi 'friend';

Category [1]: e 'picture', saru 'monkey', kitsune 'fox', urukome 'kellifish'; 
28 A Typological Study of Tonal Systems of Japanese and Prinmi:

Category [2]: yama 'mountain', usagi 'rabbit', tebukuro 'glove';

Category [3]: otoko 'male', kudamono 'fruit'; and Category [4]: kaminari 'thunder'.

\subsection{Kagoshima}

Moving south, we now turn to Kagoshima on Kyushu. The suprasegmental system of Kagoshima is quite simple, having only two categories. According to the definition proposed in Section 3, Kagoshima has not developed a full-fledged pith-accent system. If treated alone, Kagoshima could be analyzed as a word-tone language. Nonetheless, since Kagoshima is a dialect of Japanese, it is sensible to recognize it as a pitch-accent language.

As in Narada, the $\mathrm{H}$ tone does not spread in Kagoshima. The suprasegmental system of Kagoshima is analyzed as follows:

Table 11. An Analysis of the Pitch-accent System of Kagoshima Japanese, Based on Information in Hirayama (1960: 92)

\begin{tabular}{cccccc}
\hline \hline Parameter & 1-mora & 2-mora & 3-mora & 4-mora & 5-mora \\
\hline$[\mathrm{n}]$ & $\mathbf{H}$ & L-H & L-L-H & L-L-L-H & L-L-L-L-H \\
{$[\mathrm{n}-1]$} & Falling & H-L & L-H-L & L-L-H-L & L-L-L-H-L \\
\hline \hline
\end{tabular}

Some examples of words in these two categories are:

Category [n]: $\quad$ e 'picture', saru 'monkey', asahi 'morning sun', irogami 'colored paper'; and

Category [n-1]: e 'handle', mizu 'water', mukashi 'the past', kagaribi 'campfire'.

As can be seen from Table 11, one of the tonal categories always places the $\mathrm{H}$ tone on the final mora in the underlying domain, and 
the other always designates the penultimate mora in the underlying domain for the $\mathrm{H}$ tone. Since these positions are counted from the right edge of the underlying domain, a variable is necessary in the parameter specification (given the convention of counting from the left). Note that the locus of the $H$ tone as calculated from [1-1] (one minus one, for one-mora words) should be interpreted as placing the $\mathrm{H}$ tone immediately before the initial mora of the word; it does not mean to delete or discard the $\mathrm{H}$ tone. The sequence of level tones in combination results in a falling tone in one-mora words of this tonal category.

\section{The Diversity of Pitch-accent Systems}

From the analyses of Prinmi and six Japanese dialects, we saw that pitch-accent systems are rich in variety. Certain language/ dialect-specific suprasegmental rules or constraints may exist side by side with the fundamental principle that governs the organization of a pitch-accent system. Table 12 summarizes the characteristics of the pitch-accent systems observed in these languages/dialects:

The surface tones found in pitch-accent languages are predominantly level tones. Contour tones comprising a sequence of two level tones are occasionally encountered in a defective domain, where a single syllable/mora strives to preserve the shape of a tonal pattern. This occurs in Prinmi and Japanese dialects such as Kyoto, Shizukuishimachi, and Kagoshima.

Spreading of the $\mathrm{H}$ tone is the most significant factor to the diversity of pitch-accent systems. First of all, spreading is not an essential feature. In Narada, Kagoshima, and Shizukuishimachi (for completed speech), the $\mathrm{H}$ tone does not spread. Secondly, there are two possible directions for the spreading: leftward, as in Tokyo, Kyoto, and Nagoya, or rightward, as in Prinmi and Shizukuishimachi (for connected speech). Thirdly, where spreading occurs, there can 
30 A Typological Study of Tonal Systems of Japanese and Prinmi:

Table 12. A Comparison of the Pitch-accent Systems in Prinmi and Japanese

\begin{tabular}{|c|c|c|c|c|}
\hline & $\begin{array}{l}\text { Possible Pitch } \\
\text { Shape }\end{array}$ & $\begin{array}{c}\text { H-tone } \\
\text { Spreading }\end{array}$ & $\begin{array}{l}\text { Counting from } \\
\text { the Right Edge }\end{array}$ & Notes \\
\hline Prinmi & $\begin{array}{l}\text { Level, Falling, } \\
\text { Rising }\end{array}$ & $\begin{array}{l}\text { Rightward, } \\
\text { restricted }\end{array}$ & Never & \\
\hline Tokyo & Level & $\begin{array}{l}\text { Leftward, } \\
\text { restricted }\end{array}$ & Allowed & \\
\hline Kyoto & Level, Falling & $\begin{array}{l}\text { Leftward, } \\
\text { unrestricted }\end{array}$ & Allowed & \\
\hline Nagoya & Level & $\begin{array}{l}\text { Leftward, } \\
\text { restricted }\end{array}$ & Allowed & \\
\hline Narada & Level & No spreading & Never & $\begin{array}{l}\text { High-tone } \\
\text { insertion }\end{array}$ \\
\hline $\begin{array}{l}\text { Shizukuishi- } \\
\text { machi } l^{*}\end{array}$ & Level, Falling & No spreading & Never & $\begin{array}{l}\text { H-absence } \\
\text { possible }\end{array}$ \\
\hline $\begin{array}{l}\text { Shizukuishi- } \\
\text { machi } 2^{*}\end{array}$ & Level & Rightward & Never & $\begin{array}{l}\text { H-absence } \\
\text { possible }\end{array}$ \\
\hline Kagoshima & Level, Falling & No spreading & Always & \\
\hline
\end{tabular}

be a number of varying restrictions as to how far the spreading may reach. The most restrictive case is found in Prinmi, where the H tone may spread only to the adjacent syllable. Less restrictive cases are seen in Tokyo and Nagoya, where the initial mora and the first two moras are immune to spreading, respectively. The spreading can also be unrestricted, as in Kyoto and Shizukuishimachi (for connected speech).

Finally, the starting direction for H-tone placement in the underlying domain may also vary among pitch-accent languages. Prinmi, Narada, and Shizukuishimachi always count the position of the $\mathrm{H}$ tone from the left edge of the underlying domain. On the contrary, Kagoshima always counts from the right edge of the underlying domain. While counting from the left edge is the norm in Tokyo, Kyoto, and Nagoya, counting from the right edge is also possible (which results in the so-called 'unaccented' pattern) in these 
Japanese varieties. This rightmost locus is construed as such because the precise length of the underlying domain of these Japanese dialects has not been determined.

Two remarkable phenomena are observed in the survey of the Japanese dialects above. The fact that Shizukuishimachi exploits the absence of the $\mathrm{H}$ tone to form a tonal category has revealed the full range of probability, as would be possible in principle, by placing the $\mathrm{H}$ tone nowhere in the underlying domain. It helps to show a complete picture of the fundamental organization that hinges on the location of the marked tone. Secondly, it must be noted that the insertion of a non-marked high tone to the initial mora in Narada is irrelevant to its overall pitch-accent system; it is no more than an idiosyncratic modification of the suprasegmental system.

\section{Conclusion}

The traditional notion of tone is useful for distinguishing those languages that use suprasegmentals to express lexical meanings (as opposed to grammatical meanings). According to the different mechanisms and organizations of tonal contrast, the 'pitch-accent system' should be recognized as a new type of tonal system, distinct from the syllable-tone system and the word-tone system (cf., Fox 2000, Ding 2005). This paper has proposed a definition of pitch-accent system in terms of the placement of the marked tone in the underlying domain.

It should be emphasized again that the abstract underlying domain is independent of both the syllable and the word. If we take four syllables/moras as the basic length of the underlying domain, we can derive the tonal categories in a pitch-accent language by placing the marked tone on the first, second, third, and fourth syllables/moras in the domain, respectively. The marked tone shifts from a syllable/mora to the next in an orderly manner. There is no 
32 A Typological Study of Tonal Systems of Japanese and Prinmi:

accidental gap, say, leaving the second or the third position unused, and placing the marked tone only on the first and the fourth positions. Since the underlying domain is independent of the word, it is possible to designate the marked tone at a location outside the word. Once the phonological domain of the word extends, the presence of such a marked tone will become manifest. This happens in Prinmi and Narada.

From the comparison of the seven pitch-accent languages/ dialects studied in this paper, it is apparent that considerable diversity exists among different pitch-accent systems. To render typological investigation of these and other languages meaningful, we must first identify what the pitch-accent system is. There have been exciting reports of pitch-accent languages in New Guinea (Donohue 1997) and the Tibeto-Burman area (Evans 2001), in addition to those African languages discussed in McCawley (1978) and Odden (1995). However, an open question is whether they have developed a full-fledged pitch-accent system comparable to that in Japanese and Prinmi, or do they instead simply exhibit certain surface traits reminiscent of (undefined) 'pitch-accent' languages? Hopefully, the proposed definition of pitch-accent system and the discussion of the variations found in the selected pitch-accent systems will be useful in future investigation of pitch-accent languages in the world, which, in turn, would contribute to research on the typology of lexical suprasegmentals in general.

\section{References}

Akamatsu, T. 1997. Japanese Phonetics: Theory and Practice. München: Lincom Europa.

Beckman, M. 1986. Stress-accent and Non-stress-accent Accent. Dordrecht: Foris Publications.

Bogers, K., H. van der Hulst, \& M. Mous. (eds.) 1986. The Phonological 
Representation of Suprasegmentals: Studies on African Languages Offered to John M. Stewart on His 60th Birthday. Dordrecht \& Cinnaminson, NJ: Foris Publications.

Clark, M. 1986. Japanese as a Tone Language. In T. Imai \& M. Saito (eds.), Issues in Japanese Linguistics 53-105. Dordrecht: Foris Publications.

Ding, P. 1998. Fundamentals of Prinmi (Pumi): A Tibeto-Burman Language of Northwestern Yunnan. Ph.D. Dissertation. Canberra: Australian National University. . 1999. Accent vs. Tone and Evidential vs. Tense/Aspect: Lessons from Doing Fieldwork on Prinmi. Presented at the Workshop on Qiangic Languages and Linguistics. Taipei: Academia Sinica. . 2001. The Pitch-accent System of Niuwozi Prinmi. Linguistics of the Tibeto-Burman Area 24.2, 57-83.

2003a. Prinmi: A Sketch of Niuwozi. In G. Thurgood \& R. LaPolla (eds.), Sino-Tibetan Languages 588-601. London: Routledge Press.

. 2003b. A Dialectal Study of Suprasegmental Systems of Prinmi: Report from the Field. Presented at the 36th International Conference on Sino-Tibetan Languages and Linguistics. Bundoora: La Trobe University.

. 2005. Tone Languages. In P. Strazny (ed.), Encyclopedia of Linguistics 1117-1120. New York: Fitzroy Dearborn.

Donohue, M. 1997. Tone in New Guinea. Linguistic Typology 1.3, 347-386.

Duanmu, S. 1992. An Autosegmental Analysis of Tone in Four Tibetan Languages. Linguistics of the Tibeto-Burman Area 15.1, 65-91.

Evans, J. 2001. Contact-induced Tonogenesis in Southern Qiang. Language and Linguistics 2.2, 63-110.

Fox, A. 2000. Prosodic Features and Prosodic Structure: The Phonology of Suprasegmentals. Oxford: Oxford University Press.

Fu, A. 1998. Grammatical Categories of Pumi Verbs. Beijing: Chinese Cultural and Historical Publisher.

Heine, B. \& D. Nurse. (eds.) 2000. African Languages: An Introduction. 
34 A Typological Study of Tonal Systems of Japanese and Prinmi:

Cambridge: Cambridge University Press.

Hirayama, T. 1960. Dictionary of Pan-Japanese Accentuations. Tokyo: Tokyodoo Publisher.

van der Hulst, H. 1999. Word Accent. In H. van der Hulst (ed.), Word

Prosodic Systems in the Languages of Europe 3-115. Berlin: Mouton de Gruyter.

van der Hulst, H. \& N. Smith. 1988. The Variety of Pitch Accent Systems:

Introduction. In H. van der Hulst \& N. Smith (eds.), Autosegmental Studies on Pitch Accent 9-24. Dordrecht: Foris.

Inoue, O. 1930. Accentuation of Maizuru Region. Study of Sounds 3, 91-130.

Kubozono, H. 1994. Pitch-accent. In R. Asher \& J. Simpson (eds.), The Encyclopedia of Language and Linguistics 3189-3190. Oxford: Pergamon Press.

Lu, S. 1983. A Brief Account of the Pumi Language. Beijing: Nationalities Press.

2001. Dialectal Studies of the Pumi Language. Beijing: Nationalities Press.

Matisoff, J. 1997. Dayang Pumi Phonology and Adumbrations of Comparative Qiangic. Mon-Khmer Studies 27, 171-213.

Mazaudon, M. 1973. Phonologie Tamang: Étude phonologique du dialecte Tamang de Risiangku. Paris: Société d'Études Linguistiques et Anthropologiques de France. . 1977. Tibeto-Burman Tonogenetics. Linguistics of the Tibeto-Burman Area 3.2, 1-123.

McCawley, J. 1968. The Phonological Component of a Grammar of Japanese. The Hague: Mouton. . 1978. What Is a Tone Language? In V. Fromkin (ed.), Tone: A Linguistic Survey 113-131. New York: Academic Press.

Odden, D. 1995. Tone: African Languages. In J. Goldsmith (ed.), The Handbook of Phonological Theory 444-475. Oxford: Blackwell.

Refsing, K. 1986. The Ainu Language: The Morphology and Syntax of the Shizunai Dialect. Aarhus: Aarhus University Press. 
Saeed, J. 1999. Somali. Amsterdam: John Benjamins.

Shibatani, M. 1990. The Languages of Japan. Cambridge: Cambridge University Press.

Uwano, Z. 1977. Accentuations of Japanese. In S. Oono \& T. Shibata (eds.), Japanese (V): Phonology 281-321. Tokyo: Iwanami Publisher.

Wada, M. 1962. Akusento. In K. Gakkai (ed.), Introduction to Dialectology 162-208. Tokyo: Musashino Shoin.

Zee, E. 2003. Shanghai Phonology. In G. Thurgood \& R. LaPolla (eds.), Sino-Tibetan Languages 131-138. London: Routledge Press. 